\title{
ANALISIS KERUSAKAN SPAREPART PADA MESIN PLANETARY COOLER UNTUK MENGHITUNG BIAYA SPAREPART YANG RUSAK PADA INDARUNG II/III DI PT.SEMEN PADANG
}

\author{
Ir. Abd Latif, MM ${ }^{1)}$, Riko Ervil, MT $^{2)}$, Randi Zulfahli ${ }^{3)}$ \\ ${ }^{1}$ Teknik Industri, Sekolah Tinggi Teknologi Industri Padang \\ Email : rikoervil@sttind.ac.id, randizulfahli@ymail.com
}

\begin{abstract}
Abstrak
PT. Semen Padang merupakan perusahaan yang bergerak dibidang industri pengolahan bahan mentah menjadi bahan jadi dengan skala besar. Perusahaan yang berstatus BUMN (Badan Usaha Milik Negara). PT. Semen Padang merupakan salah satu perusahaan Industri di Sumatera Barat yang memproduksi Semen. Planetary Cooler merupakan alat yang digunakan oleh pabrik Semen Padang yang berfungsi untuk mendinginkan clinker pada indarung II/III di PT. Semen Padang. Untuk itu Planetary Cooler merupakan mesin yang sangat penting untuk diperhatikan. Proses pendinginan Planetary Cooler harus berjalan dengan baik agar tidak terjadi kerusakan pada Planetary Cooler yang berdampak pada terbuangnya material akan menghambat proses produksi pada Planetary Cooler. Maka dilakukan analisa peramalan kerusakan komponen dan penentuan biaya untuk tahun 2018. Sehingga diperoleh hasil dengan menggunakan mini tab 16. Data hasil peramalan yang didapatkan yaitu Batu tahan api 10, Lifter 6, Tapak 8, Baut 4 dan Filter 10. harga yang dikeluarkan untuk komponen batu tahan api yaitu sebesar Rp 2.000.000, biaya lifter sebesar Rp 408.000, biaya tapak sebesar Rp 224.000, biaya baut sebesar Rp 48.000 dan biaya filter sebesar Rp 15.000.000. Jadi total biaya perawatan yang dikeluarkan perusahan pada tahun 2018 sebesar Rp 17.680.000.
\end{abstract}

Kata Kunci : Planetary Cooler, Time Series, Failure cost, Preventive Cost.

\section{PENDAHULUAN}

Saat ini dunia telah memasuki era globalisasi dimana tidak ada lagi penghalang antara negara-negara di seluruh dunia. Era globalisasi ini ditandai dengan berlangsungnya perdagangan bebas yang mengakibatkan semakin ketatnya persaingan dunia bisnis. Untuk menyikapi hal tersebut, maka setiap perusahaan dituntut untuk selalu memperbaiki setiap departemen dan proses yang ada di dalamnya.

Usaha perbaikan pada industri manufaktur, dilihat dari segi peralatan, adalah dengan meningkatkan utilisasi peralatan yang ada seoptimal mungkin. Utilisasi dari peralatan yang ada pada ratarata industri manufaktur adalah sekitar setengah dari kemampuan mesin yang sesungguhnya. Pada prakteknya, Seringkali usaha perbaikan yang dilakukan tersebut hanya pemborosan, karena tidak menyentuh akar permasalahan yang sesungguhnya.

Hal ini disebabkan karena tim perbaikan tidak mendapatkan dengan jelas permasalahan yang terjadi dan faktorfaktor yang menyebabkannya. Untuk itu diperlukan suatu metode yang mampu mengungkapkan permasalahan dengan jelas agar dapat melakukan peningkatan kinerja peralatan dengan optimal

Tempat melakukan tugas akhir ini adalah PT. Semen Padang yang selama ini telah menerapkan suatu metode pengukuran kinerja manufaktur perusahaan. Melalui metode tersebut, perbaikan yang berkelanjutan (continuous improvement) terhadap peningkatan kinerja peralatan terus dilakukan. Seiring dengan pelaksanaan usaha perbaikan tersebut, masih dijumpai permasalahan yang mengakibatkan tidak optimalnya peningkatan kinerja peralatan. Dengan demikian, pada tugas akhir ini pokok permasalahan yang dibahas adalah 
mengenai kerusakan spare part dan penentuan biaya komponen mesin Planetary Cooler.

Planetary Cooler merupakan alat yang diaplikasikan oleh pabrik semen yang berfungsi pendingin dan pengurai klinker. planetary cooler sama seperti pada rotary cooler dimana clinker di umpankan melalui inlet chute dan kemudian di dinginkan oleh udara ketika ditransport menuju outlet. Pendinginan terjadi di dalam aliran counter-current. Tube dilengkapi dengan internal lifter yang meningkatkan perpindahan panas dan sekitar $66 \%$ dari panjang cooler dilengkapi dengan refractory brick. Perbedaan mendasar dari planetary cooler dengan rotary cooler adalah jumlah cooling tube-nya. Pada planetary cooler, aliran clinker dibagi menjadi 9-11 (biasanya 10) cooling tube yang dipasang di sekitar kiln pada outlet kiln. Oleh karena itu, planetary tube mengikuti rotasi kiln. Planetary cooler tidak membutuhkan penggerak terpisah karena berhubungan dengan rotasi kiln dimana fakta ini sudah menggambarkan satu keuntungan utama dari planetary cooler yaitu kemudahan dalam pengoperasian.

Ditemui permasalahan yang terjadi di area mesin planetary cooler seperti kerusakan pada komponen planetary cooler, komponen yang mengalami kerusakan yaitu: batu tahan api, lifter, tapak, baut, filter, dari batu tahan api 1000 pcs dengan biaya Rp 200.000 pcs,lifter 294 pcs dengan biaya Rp 68.000 pcs,tapak 294 pcs dengan biaya Rp 28.000 pcs, baut 294 pcs dengan biaya Rp 12.000 pcs, dan filter 1 pcs dengan harga Rp 1.500.000 pcs. yang mengakibatkan biaya pergantian spare part dari tahun ke tahun selalu tidak tetap karena tidak adanya data pasti berapa spare part yang di butuhkan untuk kerusakan mesin planetary cooler setiap tahunnya dan apabila mesin kiln stop/breaking maka proses produksi akan berhenti yang mengakibatkan pihak perusahaan akan mengalami kerugian.
Sejak awal berdirinya, perusahaan ini terus menerus berusaha memperbaiki kinerja elemen-elemen yang ada didalamnya agar dapat meningkatkan efektifitas dari peralatan, perusahaan juga perlu memperbaiki peralatan yang digunakan untuk mempertahankan kondisi peralatan tetap berfungsi dengan baik dan lancar. Kemampuan bertahan dan terus berkembang yang dituntut haruslah dapat dipenuhi karena era persaingan yang ketat agar perusahaan semakin dinamis

Tujuan dalam penelitian ini adalah Meramalkan kerusakan spare part pada mesin Planetary Cooler tahun 2018 pada Indarung II/III di PT. Semen Padang dan menentukan biaya kerusakan Spare Part mesin Planetary Cooler tahun 2018 pada Indarung II/III di PT.Semen Padang.

\section{METODE PENELITIAN}

Jenis penelitian yang dilakukan adalah penelitian deskriptif yaitu penelitian yang berusaha untuk memberikan rekomendasi untuk keperluan pada masa yang akan datang dan juga memaparkan pemecahan masalah terhadap suatu masalah yang ada sekarang secara sistematis dan faktual berdasarkan data-data. Penelitian ini dilakukan di PT. Semen Padang tepatnya di Indaruang II/III sedangkan waktu penelitian ini dilakukan pada bulan Juni 2018. Dalam penelitian ini data yang digunakan adalah data kerusakan spare part dan data biaya kerusakan spare part tiga tahun lalu.

\section{HASIL DAN PEMBAHASAN Peramalan Kerusakan Spare Part Pada Mesin Planetary Cooler Tahun 2018}

Peramalan dilakukan dengan menggunakan program minitab 16 dan data-data kerusakan spare part dimasukkan ke dalam program lalu dapatkan hasil peramalan untuk tahun berikutnya. Adapun hasil peramalan yang telah diproses oleh program minitab adalah sebagai berikut: 


\section{Batu tahan api}

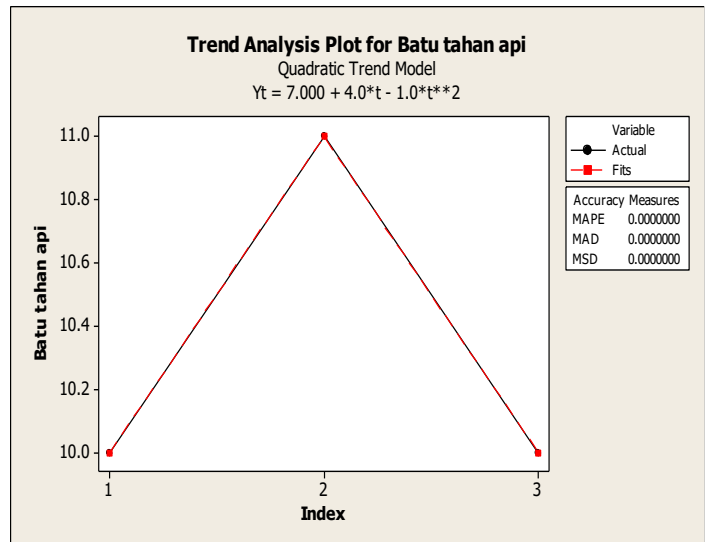

Gambar 1. Peramalan Batu Tahan Api Dengan Metode Trend Quadratic Tahun 2018

Maksud dari MAD, MAPE dan MSD adalah kesalahan (error) dalam peramalan. Dalam hal ini dapat dikatakan bahwa kesalahan dalam peramalan adalah $0 \%$. Metode peramalan hubungan deret waktu dengan Model Quadratic karena memiliki nilai MAD, MAPE dan MSD yang lebih kecil dibandingkan model linier.

Jadi komponen yang dibutuhkan pada tahun 2018 adalah sebanyak 10 komponen dan perusahaan bisa lebih mudah mengatur pembelian komponen pertahun.

\section{Lifter}

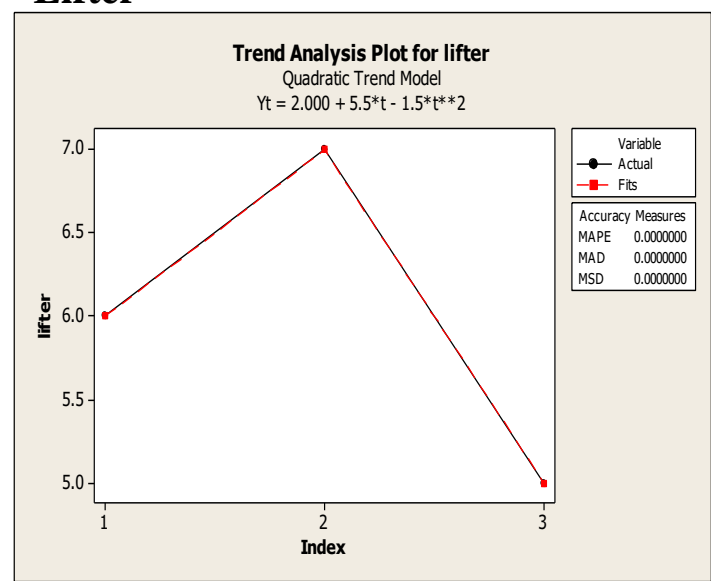

Gambar 2. Peramalan Lifter Dengan Metode Trend Quadratic Tahun 2018

Dalam hasil peramalan lifter diatas nilai MAD, MAPE dan MSD adalah 0\%. Metode peramalan hubungan deret waktu dengan Model Quadratic karena memiliki nilai MAD, MAPE dan MSD yang lebih kecil dibandingkan model linier.oleh karena itu pada peramalan komponen lifter masih menggunakan quadratic model

Jadi komponen yang dibutuhkan pada tahun 2018 adalah sebanyak 6 komponen dan perusahaan bisa lebih mudah mengatur pembelian komponen pertahun.

\section{Tapak}

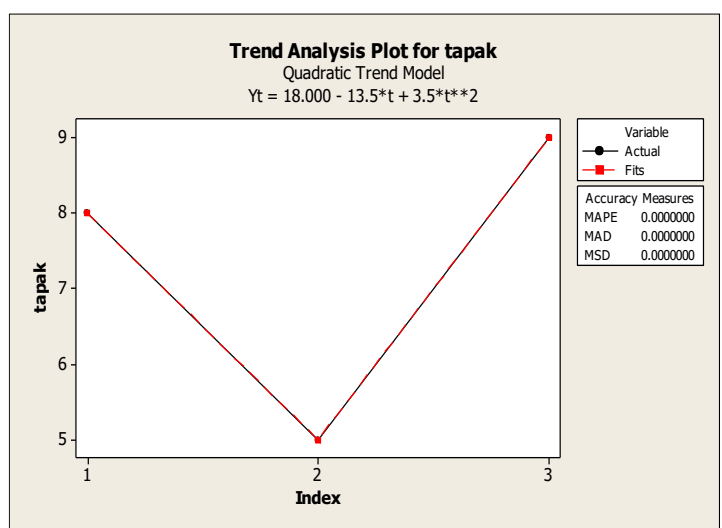

Gambar 3. Peramalan Tapak Dengan Metode Trend Quadratic Tahun 2018

Dalam hasil peramalan tapak nilai MAD, MAPE dan MSD adalah 0\%. Metode peramalan hubungan deret waktu dengan Model Quadratic karena memiliki nilai MAD, MAPE dan MSD yang lebih kecil dibandingkan model linier. Oleh karena itu pada peramalan komponen tapak masih menggunakan quadratic model.

Jadi komponen yang dibutuhkan pada tahun 2018 adalah sebanyak 8 komponen.

\section{Baut}

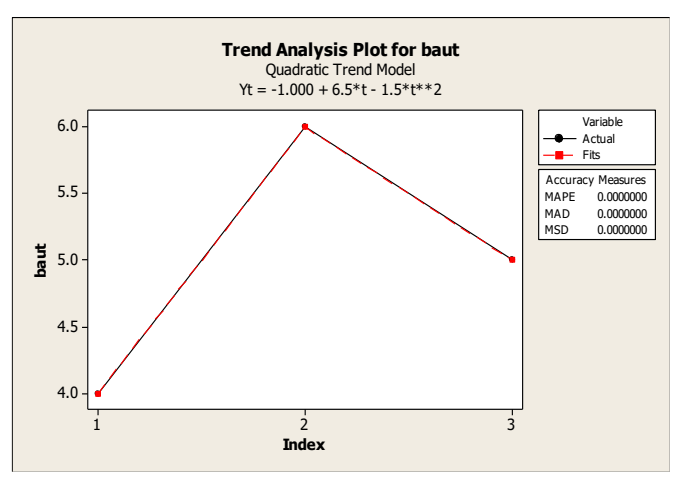

Gambar 4. Peramalan Baut Dengan Metode Trend Quadratic Tahun 2018 
Dalam hasil peramalan baut diatas nilai MAD, MAPE dan MSD adalah 0\%. Metode peramalan hubungan deret waktu dengan Model Quadratic karena memiliki nilai MAD, MAPE dan MSD yang lebih kecil dibandingkan model linier.oleh karena itu pada peramalan komponen baut masih menggunakan quadratic model

Jadi komponen yang dibutuhkan pada tahun 2018 adalah sebanyak 4 komponen dan perusahaan bisa lebih mudah mengatur pembelian komponen pertahun.

\section{Filter}

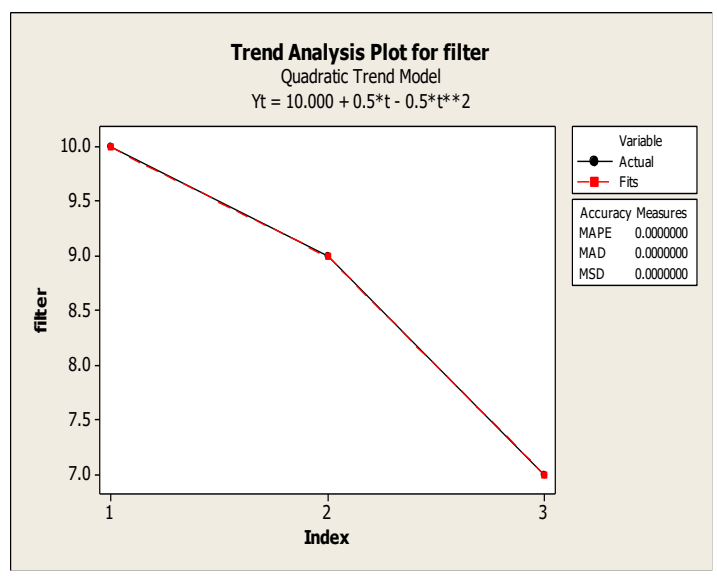

Gambar 5. Peramalan Filter Dengan Metode Trend Quadratic Tahun 2018

Dalam hasil peramalan Filter diatas nilai MAD, MAPE dan MSD adalah $0 \%$. Metode peramalan hubungan deret waktu dengan Model Quadratic karena memiliki nilai MAD, MAPE dan MSD yang lebih kecil dibandingkan model linier.oleh karena itu pada peramalan komponen filter masih menggunakan quadratic model

Jadi komponen yang dibutuhkan pada tahun 2018 adalah sebanyak 10 komponen dan perusahaan bisa lebih mudah mengatur pembelian komponen pertahun.

Setelah dilakukan peramalan untuk semua spare part kemudian hasil peramalan untuk tahun 2018 di rekap kedalam sebuah tabel. Adapun tabel hasil peramalan secara keseluruhan adalah sebagai berikut:
Tabel 1. Hasil Peramalan Spare Part Tahun 2018

\begin{tabular}{|c|c|}
\hline Spare Part & $\mathbf{2 0 1 8}$ \\
\hline Batu tahan api & 10 \\
\hline Lifter & 6 \\
\hline Tapak & 8 \\
\hline Baut & 4 \\
\hline Filter & 10 \\
\hline
\end{tabular}

Dari tabel diatas, dapat dilihat komponen yang dibutuhkan untuk pergantian kerusakan spare part pada mesin planetary cooler untuk tahun 2018. Jadi perusahaan dapat mengambil spare part yang dibutuhkan selama satu tahun di work shop PT. Semen Padang tanpa harus menunggu mesin rusak terlebih dahulu karena telah dilakukan peramalan berapa komponen yang dibutuhkan untuk pergantian kerusakan pada mesin planetary cooler dalam kurun waktu 1 tahun.

\section{Menentukan Biaya Pergantian Spare Part Tahun 2018}

Dalam penentuan biaya kerusakan spare part tahun 2018, data-data yang digunakan adalah data biaya spare part per pcs dan data hasil peramalan spare part pada tahun 2018. Adapun langkah-langkah penentuannya adalah sebagai berikut :

Biaya spare part per pcs :

1. Batu tahan api : Rp 200.000/Pcs

2. Lifter $: \operatorname{Rp} 68.000 / \mathrm{Pcs}$

3. Tapak : Rp 28.000/Pcs

4. Baut : Rp 12.000/Pcs

5. Filter $:$ Rp 1.500.000/Pcs

Biaya pergantian spare part pada mesin planetary cooler pada tahun 2018 adalah sebagai berikut :

1. Batu tahan api

Rp 200.000/Pcs x $10=$ Rp 2.000.000

2. Lifter

Rp 68.000/Pcs x $6=R p \quad 408.000$

3. Tapak

Rp 28.000/Pcs x $8=R p \quad 224.000$

4. Baut

$\operatorname{Rp} 12.000 / \operatorname{Pcs} x 4=R p \quad 48.000$ 
5. Filter

Rp $1.500 .000 / \operatorname{Pcs} x 10=\frac{R p 15.000 .000}{R p 17.680 .000}$

Jadi, biaya yang dibutuhkan untuk pergantian spare part pada mesin planatery cooler pada tahun 2018 adalah sebesar 17.680.000. perusahaan bisa mengatur biaya yang di keluarkan di awal tahun tanpa adanya biaya pengambilan spare part tambahan di work shop pada saat kerusakan mesin terjadi.

\section{KESIMPULAN}

Dari tujuan penelitian meramalkan kerusakan spare part pada mesin Planetary Cooler tahun 2018 pada Indarung II/III di PT. Semen Padang dan menentukan biaya kerusakan Spare Part mesin Planetary Cooler tahun 2018 pada Indarung II/III di PT.Semen Padang dapat ditarik kesimpulan hasil peramalan yang dilakukan dengan program mini tab $16 \mathrm{di}$ dapatkan spare part yang dibutuhkan dalam 1 tahun, seperti batu tahan api 10 pcs, lifter 6 pcs, tapak 8 pcs, baut 4 pcs dan filter 10 pcs dan hasil biaya perawatan yaitu biaya batu tahan api sebesar $\mathrm{Rp}$ 2.000.000, biaya lifter sebesar Rp 408.000, biaya tapak sebesar Rp 224.000, biaya baut sebesar $\mathrm{Rp} 48.000$ dan biaya filter sebesar Rp 15.000.000. Jadi total biaya perawatan yang dikeluarkan perusahan pada tahun 2018 sebesar Rp 17.680.000.

\section{DAFTAR PUSTAKA}

Antares, Vega Prima. Pengaruh factor Fundamental dan Faktor Teknikal terhadap harga Saham pada perusahaan Manufaktur yang go Publik, Sekolah Tinggi Perbanas, Surabaya. 2010.

Assauri, Sofyan. Teknik dan metode peramalan. Jakarta. Fakultas Ekonomi universitas indonesia. 1984.

Biegel, Jhon E.Suatu Pendekatan Kuantitatif pada Pengendalian Produksi. Jakarta. 1992.
Corder, A. S. Teknik Mnajemen Pemeliharaan, Eirlangga, Jakarta. 1992.

Ervil, Riko, dkk. Buku Panduan Penulisan Dan Ujian Skripsi. STTIND Padang. Padang. 2013.

Gasper, Vincent. Analisa Sistem Terapan Berdasarkan Terapan industri. Penerbit Edisi pertama. Tarsiton Bandung. 1992.

Gasper, Vincent. Metode Analisis Untuk Meningkatkan Kualitas, Gramedia Pustaka Utama, Jakarta. 2001.

Gasper, Vincent. Total Quality Management, Gramedia Pustaka Utama, Jakarta. 2004.

Kurniawan, fajar. Manajemen Perawatann Industri. Buku beta. Jogjakarta. 2013.

Manzini, R. Maintanance For Industrial System, Springel, London. 2010.

Nachnul, Anshori, dan M.Imron, Mustajib. Sistem Perawatan Terpadu. Graha Ilmu, Yokyakarta. 2013.

Sudradjat, Ahmad. Pembelajaran dengan Pendekatan Ilmiah, Puistaka Ilmu, Palembang. 2013.

Sudradjat, M. Subana. Dasar - dasar Penelitian Ilmiah, Pustaka Setia, Bandung. 2011.

Yulianto, Ahmad. Dualisme penelitian hokum Normatif dan Emperis. Pustaka Belajar, Yokyakarta, 2012 